Ángulo Recto. Revista de estudios sobre la ciudad como espacio plural

ISSN: $1989-4015$

\title{
Ciudades sin palabra: silencio y destrucción en la Alemania de posguerra
}

Federico Guzmán Rubio ${ }^{1}$

Recibido: 15/09/2017 / Aceptado: 15/04/2018

Resumen. Nunca en su historia Alemania había experimentado tal devastación como la que dejaron en sus ciudades los bombardeos aéreos al final de la Segunda Guerra Mundial. A pesar de su magnitud, prácticamente no hay fuentes que hablen sobre este desastre, y su ausencia de la memoria histórica alemana resulta inquietante. Pensadores como Enzensberger (2013) y Sebald (2003) han formulado respuestas que la explican. A partir de sus reflexiones, el presente artículo pretende leer dos testimonios sobre este periodo, Ningún lugar adonde ir, del lituano Jonas Mekas, y El daño oculto, del irlandés James Stern, con el objetivo de indagar la naturaleza de dicho silencio, bajo la hipótesis de que mientras ambos autores contemplaban la destrucción, también atestiguaban la construcción de un olvido deliberado.

Palabras clave: Posguerra alemana; Jonas Mekas; James Stern; memoria histórica.

\section{[en] Speechless Cities: Silence and Destruction in German Postwar}

Abstract. Germany had never experienced such devastation as the one that the air raids left in its cities at the end of Second World War. Despite its magnitude, there are almost no documentary sources that deal with this disaster, and its absence in German historic memory is disturbing. Thinkers such as Enzensberger (2013) and Sebald (2003) have built theories that analyze this phenomenon. From their reflections, the current paper pretends to read two testimonies of this period, I Had Nowhere to Go, by the Lithuanian artist Jonas Mekas, and The Hidden Damage, by Irish writer James Stern, with the purpose of understanding this silence, with the hypothesis that as both authors looked the destruction, they also witnessed the conformation of an intentional oblivion.

Keywords: German postwar; Jonas Mekas; James Stern; historic memory.

\section{La constatación de una ausencia}

Sorprende, dentro de la inabarcable bibliografía sobre la Segunda Guerra Mundial, la relativa ausencia de testimonios sobre el paisaje de destrucción física y moral que dejó la conflagración en el territorio europeo. Este silencio, por supuesto, resulta muy elocuente, y dice más, y sobre todo algo radicalmente diferente, que las ingentes páginas en que se narran combates y batallas de todos los frentes. Porque esta ausencia, además, no solo está presente en obras de carácter historiográfico, sino que también abarca la literatura testimonial y la ficcional.

Hay excepciones, claro está, y relativamente numerosas; sin embargo, dada la envergadura del periodo en cuestión, en que se sentaron las bases no solo de la reconstrucción europea, sino de su posterior unión y de la fragilidad de esta, además del caldo de cultivo de la Guerra Fría, estos textos siguen siendo excepcionales. Pero más allá del interés académico que despierten como rarezas, su importancia primordial radica en que se erigen, de manera involuntaria, como las pocas fuentes de estudio para enfrentarse a un periodo histórico muy breve, pero esencial para entender la segunda mitad del siglo XX e, incluso, a la Europa contemporánea.

El periodo en cuestión, el de la posguerra, abarca de mayo de 1945, cuando termina la guerra en el continente, a abril de 1948, cuando comienza la implementación del Plan Marshall, y con él la reconstrucción a gran escala de Europa occidental. En este mismo año, también, los tres sectores occidentales de Alemania, bajo control de Estados Unidos,

1 Departamento Académico de Lenguas.

Instituto Tecnológico Autónomo de México (ITAM).

federico.guzman@itam.mx 
Francia e Inglaterra, se unifican y forman la República Federal de Alemania (RFA), mientras que el sector ruso, un año después, se convertiría en la República Democrática Alemana (RDA). Este acontecimiento podría situarse como el inicio de la extensa Guerra Fría, y, por tanto, como el punto final de la posguerra. De esta forma, estrictamente, la posguerra europea ocupa tan sólo tres años, un breve lapso que, probablemente, por considerársele de mera transición, no ha generado la cantidad de estudios que merecería (otra vez, en comparación con otros aspectos de la Guerra, que constituyen incluso un subgénero en la industria editorial y filmográfica).

Dicho vacío historiográfico y testimonial se vuelve todavía más visible en Alemania, a pesar de que, discutiblemente, la catástrofe de la guerra haya constituido un trauma más profundo en esta nación, por el simple hecho de tratarse de algo inédito. Una buena parte de Europa ya había conocido en territorio propio una devastación sin precedentes en la Primera Guerra Mundial, mientras que Alemania había sorteado el siglo XX sin padecerla dentro de sus fronteras. A ello, habría que agregar que, si cabe, la población alemana sufrió los bombardeos y la invasión de los aliados con mayor azoro, casi como un fenómeno inexplicable, pues hasta fechas muy tardías no consideraba la derrota como una posibilidad factible, y Alemania terminó siendo la gran derrotada de la Guerra.

Junto con la ausencia de fuentes directas y contemporáneas, factuales o incluso ficcionales, también sorprende que no se haya reparado en este hecho hasta la década de los noventa, medio siglo después de los acontecimientos. En esta década, se publican dos libros fundamentales que, en primer lugar, muestran su extrañeza ante este llamativo silencio y, en segundo término, inten$\tan$ formular una hipótesis que lo explique, es decir, interpretar lo no dicho. Para tal fin, además, rescatan y leen, con plena conciencia de su carácter atípico, los pocos textos que hablan no del combate y del proceso de destrucción europeo, sino de lo que vino inmediatamente después: el paisaje de después de la batalla, las ruinas todavía habitadas sobre las que se construiría, literalmente, la Europa de hoy en día. Estos libros son Europa en ruinas, de H. M. Enzensberger, publicado en 1990, y Sobre la historia natural de la destrucción, de W. G. Sebald, publicado en 1999. Fue justamente la lectura de ambos libros lo que dio pie a esta investigación, que, en un principio, partió de la inquietud de buscar nuevas voces que hicieran un poco menor el vacío que conforma el periodo de posguerra, sobre todo, por ser el más pronunciado, el del caso alemán, en especial en lo concerniente a las ciudades que fueron arrasadas por los bombardeos aliados en un corto periodo, con el fin oficial de desmoralizar a la población civil y, quizás, también como una represalia por los estragos cometidos en Europa ${ }^{2}$.

De esta forma, tras un repaso bibliográfico, se seleccionaron dos fuentes ${ }^{3}$ de procedencias muy disímiles, tanto por su origen geográfico como por el lugar desde el que se escriben, que resultan extrañamente complementarias: Ningún lugar adonde ir, del lituano Jonas Mekas, publicado en 1991; y El daño oculto, del irlandés James Stern, publicado en $1947^{4}$. Su lectura, siempre teniendo presentes las reflexiones de Enzensberger y Sebald, en una segunda etapa, permitió establecer una hipótesis de trabajo: los pocos testimonios disponibles sobre el corto periodo que media entre la rendición de la Alemania Nazi y el establecimiento de la RFA y la RDA, además de dar cuenta de la aniquilación premeditada de los principales centros urbanos alemanes, que así se instituyen en metáfora exacta de la sociedad alemana, y de las particularidades de dicha aniquilación, explican también el silencio que ya se empezaba a construir en torno a las ruinas. Esta característica es particularmente visible en los dos textos seleccionados.

\section{El descubrimiento del silencio}

El prólogo de Enzensberger a su recopilación de la catástrofe trasciende el papel de un prólogo tradicional, pues explica el carácter extraordinario de los textos seleccionados que, de otra forma, podrían leerse como tantos testimonios del horror escritos en un siglo especialmente

\footnotetext{
Sebald centra su ensayo en la reacción alemana a los bombardeos aliados a gran escala. Estos consistieron en la destrucción premeditada de 131 ciudades alemanas, con la intención oficial de desmoralizar a la población civil, y también con el propósito de hacerle experimentar parte del horror que ella había provocado. De esta forma, a veces en una sola noche, diversas ciudades alemanas fueron devastadas con bombardeos aéreos a una escala nunca antes vista, que causaron unas seiscientas mil víctimas civiles, y dejaron sin hogar a siete millones de personas.

Ambos textos son relatos de viajes, género que permite ser tomado en cuenta como testimonio, gracias al pacto de verosimilitud que se establece entre autor y lector, similar al pacto autobiográfico estudiado por Lejeune (1975).

4 El orden de aparición de las dos fuentes responde al orden cronológico en que los escritores recorrieron Alemania: Mekas llega a Alemania en 1944; Stern, en 1945.
} 
proclive a la violencia totalitaria y total. Enzensberger escribe desde una doble extrañeza: la de constatar la falta de interés en estudiar un periodo clave de la historia europea y la de enfrentarse a una llamativa pobreza de fuentes documentales.

Sobre el primer punto, opina que se debe a una doble indiferencia: una, la del lector o estudioso contemporáneo, motivada por temor a recuperar un pasado radicalmente incómodo y vergonzoso; y, la otra, la de los protagonistas de la historia -protagonismo que consistió esencialmente en haber sobrevivido y seguir sobreviviendo-, por falta de interés y de oportunidad de registrar su situación trágica. Resulta, entonces, prioritario recuperar esa memoria olvidada y silenciada, ya que justamente en ese vacío se ubica la fundación de la Europa actual $^{5}$, que se quiere construir como una unidad:

Cincuenta años tras la catástrofe, Europa se entiende más que nunca como un proyecto común; sin embargo, aún está muy lejos de haber llevado a cabo un análisis complejo de los 'años fundacionales' después de la Segunda Guerra Mundial. El recuerdo de esa época es incompleto y provinciano, si es que no ha caído totalmente en el olvido o en la nostalgia. Y esto no solo tiene que ver con el hecho de que por aquel entonces cada uno estaba pendiente de su propia supervivencia y apenas se ocupaba de lo que estaba sucediendo a su alrededor; también está relacionado con el hecho de que no nos gusta hablar de los muertos que tenemos en los armarios. (Enzensberger 2013: 24-25)

Justificar el ejercicio de memoria no requiere mayor esfuerzo, más si se trata de un periodo de tal trascendencia. Para llevarlo a cabo, no obstante, el intelectual alemán se topa con una enorme dificultad inicial: la inexplicable falta de fuentes. Las más evidentes, que hubieran sido los análisis de todos los especialistas técnicos que proyectaban la reconstrucción de Europa, así como los artículos de opinión de periódicos y revistas que analizaran la pertinencia y viabilidad de estos proyectos, son inusualmente pobres y superficiales. Por suerte,

Obviamente, el pacifismo sobre el que se cimienta la UE, para el que ha sido determinante el pacifismo alemán, puede quebrarse en cualquier momento, y nada garantiza que el militarismo no vuelva a resultar una tentación para el espíritu alemán (Bessel 2012). existe una excepción a este panorama: la de los reportajes y testimonios que escribieron los pocos reporteros que por entonces atravesaron Europa. Es gracias a ellos, según el pensador alemán, que aún es posible realizar un ejercicio de memoria y análisis:

Quien se quiera dedicar a estudiar los artículos de opinión publicados, con la esperanza de que le proporcionen una visión más nítida de la situación en la Europa de aquel entonces, sufrirá otras decepciones. Apenas hallará juicios sobrios, análisis inteligentes, reportajes convincentes en las columnas de los periódicos y revistas de los años 1945 a 1948. [...] En las capitales de las potencias vencedoras estaban trabajando por aquel entonces numerosas planas mayores de políticos, economistas y sociólogos cuyo objetivo era hacer predicciones sobre la futura evolución de Europa. Es asombroso constatar que los informes de los mejores reporteros que estaban recorriendo por su cuenta y riesgo el continente y que confiaban meramente en sus ojos y oídos, superan con creces los análisis de todos esos especialistas. (Enzensberger 2013: 21)

A Enzensberger le llama la atención que las fuentes más ricas sean extranjeras, miradas hasta cierto punto ajenas al conflicto. No hay, como en el caso de la literatura concentrataria, testimonios escritos por las propias víctimas o sobrevivientes $^{6}$. Esta situación es especialmente visible en Alemania, puesto que, al tiempo que los alemanes acaban de sufrir en carne propia el horror de la guerra, que millones de refugiados deambulaban sin rumbo fijo y que la invasión rusa y los bombardeos aliados se habían cobrado decenas de miles de víctimas civiles, la realidad del nazismo era cada vez más conocida, innegable y, tras la derrota, vergonzosa. De ahí que, según Enzensberger, el silencio sea deliberado: "Los afectados son los peores testigos. Se atrincheran tras una amnesia colectiva. La realidad no solo es ignorada,

\footnotetext{
Además de por su abundancia y por su incalculable valor histórico, como se sabe, los testimonios de los supervivientes de los campos de concentración nazis destacan por su calidad literaria. Algunos de ellos, además de las experiencias límite que describen, constituyen verdaderas obras literarias que trascienden el mero registro histórico; tal es el caso, por ejemplo, de las obras de Primo Levi, Jorge Semprún, Imre Kertész, Tadeus Borowsky y Paul Celan.
} 
sino simple y llanamente negada" (Enzensberger 2013: 17). Y si bien resultaría exagerado e injusto culpar a toda la población alemana de cometer un olvido intencional, en una especie de pacto de silencio, hubo también una imposibilidad casi física de describir el presente: "Evidentemente, no solo había quedado devastado el entorno físico, sino también la capacidad de percepción" (Enzensberger 2013: 20).

Por el contrario, la mirada de los extranjeros, sobre todo de reporteros y escritores estadounidenses que siguieron al Ejército aliado, es confiable, y su intención explícita era describir, ya sea para un medio en especial o de manera independiente, el espectáculo de devastación y caos con el que se encontraban: "Existen muchas razones para pensar que la mirada del outsider es la que nos proporciona la transmisión más segura" (Enzensberger 2013: 20). Además de que estos testigos no tenían ningún interés en callar (al contrario, su labor era decir) y de que su capacidad de percepción no se encontraba dañada (al contrario, estaban ahí justamente para percibir), provenían de un mundo, Estados Unidos, mucho más parecido a la contemporaneidad occidental que a la Europa de ese momento: un mundo ordenado, sin escasez, sin ruinas, sin miedo, en el que regía un estado de derecho. Este contraste entre caos y orden, entre anarquía y gobierno, entre ruina y construcción, provocaba que la impresión de estos testigos fuera aún más dramática: mientras que el europeo ya no se sensibilizaba ante la devastación, por haberla naturalizado, el estadounidense era más susceptible a percibirla y verse afectado por ella. Por si fuera poco, el europeo y sobre todo el alemán, ocupado en sobrevivir, preocupado por callar, temeroso de las represalias rusas, tenía las percepciones alteradas por el profundo cambio de sistema que estaba experimentando, mientras que el observador extranjero "no se atiene a las reglas gramaticales de la ideología, sino al detalle elocuente" (Enzensberger 2013: 21).

Mediante estos testimonios extranjeros, $\mathrm{y}$ ante el silencio propiamente alemán pero también europeo, Enzensberger concluye que la aniquilación de las ciudades era perfectamente trasladable al estado de la sociedad, y viceversa, es decir, que el paisaje devastado era la escenificación del espíritu social: "Las sociedades europeas semejaban ciudades destruidas de las cuales se habían conservado planos detallados y páginas del catastro" (Enzensberger 2013: 25). La analogía del pensador alemán resulta especialmente fecunda para leer las dos fuentes rescatadas en este artículo, pues las descripciones de lo que quedó de las ciudades se puede trasladar a la perfección a la sociedad, y el estado social que describen solo podría representarse mediante un montón de escombros en los que ya ni siquiera es posible imaginarse el edificio que les dio origen.

Tan solo siete años después, en una serie de conferencias dictadas en Zurich, que luego serían recopiladas en Sobre la historia natural de la destrucción, W. G. Sebald trata el mismo tema que Enzensberger, pero concibiéndolo como un fenómeno exclusivamente alemán ${ }^{7}$. Antes que nada, Sebald expresa su consternación por este vacío histórico ${ }^{8}$, y lo hace como alemán, utilizando la primera persona del plural:

Aquella aniquilación hasta entonces sin precedente en la Historia, pasó a los anales de la nueva nación que se reconstruía sólo en forma de vagas generalizaciones y parece haber dejado únicamente un rastro de dolor en la conciencia colectiva; quedó excluida en gran parte de la experiencia retrospectiva de los afectados y no ha desempeñado nunca un papel digno de mención en los debates sobre la constitución interna de nuestro país. (Sebald 2003: 14)

Inmediatamente después, Sebald formula hipótesis sobre los posibles motivos de esta ausencia; propone, por ejemplo, que no hubo tiempo para la reflexión y ni siquiera para la mirada, debido a la premura con la que empezaron las labores de reconstrucción: "El reverso de esa apatía fue la declaración del nuevo comienzo, el indiscutible heroísmo con que se abordaron sin demora los trabajos de desescombro y reorganización" (Sebald 2003: 15). Pero este entusiasmo por la reconstrucción, aparte del genuino deseo de levantar, literal y metafóricamente, una ciudad nueva, no es inocente ni espontáneo: detrás del acto de re-

Enzensberg no reparó en la peculiaridad del silencio alemán, a pesar de que, de los sesenta y cinco testimonios que reúne en su antología, solo doce se refieren a Alemania. Asimismo, las actitudes y los motivos de los supervivientes de la Guerra, naturalmente, varían mucho dependiendo de si pertenecían al bando derrotado o al triunfante.

Es llamativo que exista una percepción de que pocos pueblos como el alemán cultivan la memoria histórica (ver, por ejemplo, Ley Brandt 2009), cuando un análisis mínimamente profundo muestra lo contrario. 
construir se encuentra también el de olvidar. Las ruinas no dejaban de ser un terrible significante, la constatación permanente y concreta de la derrota y de una venganza cruel pero justificada: "mediante la productividad exigida y la creación de una nueva realidad sin historia, se orientó a la población exclusivamente hacia el futuro y la obligó a callar sobre lo que había sucedido" (Sebald 2003: 17).

Pocas veces en la historia un pueblo se había entregado con tal convicción a la labor casi física de construir un olvido, una amnesia, cuestionable en términos históricos e incluso morales, pero quizás necesario, ya que la otra alternativa, la de la memoria, probablemente hubiera significado la inmovilidad y la perpetuidad de ese limbo al fin breve que constituyó la posguerra alemana. Sebald sostiene la teoría de que el silencio fue consensuado, y la recompensa por respetarlo consistió en una nueva ciudad y, por lo tanto, en un nuevo futuro: "A causa de un acuerdo tácito, igualmente válido para todos, no había que describir el verdadero estado de ruina material y moral en que se encontraba el país entero" (Sebald 2003: 19).

Al restringirse al ámbito alemán, a diferencia de Enzensberger, Sebald solo encuentra una verdadera excepción: El ángel callaba, de Herman Böll. Si bien se trata directa y profundamente el tema en cuestión, no puede dejar de señalarse que se trata de una novela abiertamente ficcional, cuya publicación, encima, ocurrió casi cuarenta años después de los hechos descritos. Aunque nunca lo dice abiertamente, Sebald le da la razón a Enzensberger en que los únicos testimonios sobre la posguerra alemana son los extranjeros ${ }^{9}$, y solo a ellos se podrá recurrir para intentar entender qué sucedió en esos años de transición, en ese limbo del que nunca nadie, ni entonces ni ahora, ha querido hablar.

\section{Diario de una resurrección}

Jonas Mekas ${ }^{10}$, al igual que los testigos seleccionados por Enzensberger, es extranjero; no

\footnotetext{
Curiosamente, el texto más conocido sobre los bombardeos aliados a la población civil alemana es una novela estadounidense de ciencia ficción: Matadero 5, de Kurt Vonnegut, quien sobrevivió a los bombardeos de Dresde, donde era prisionero de guerra.

10 Jonas Mekas (1922) es conocido sobre todo como cineasta experimental, pieza central en la escena artística neoyorquina de los años sesenta y setenta. Sus películas influenciaron profundamente a cineastas como John Cassavetes y artistas como Andy Warhol.
}

obstante, la naturaleza de su mirada es radicalmente distinta a la de los autores que lee el pensador alemán. Mekas no es un reportero que viaja para ver; no es un espectador profesional. De hecho, es todo lo contrario: es un espectador involuntario, que hubiera preferido no ver.

Mekas tiene que abandonar Lituania, en compañía de su hermano, por temor a ser capturado por los alemanes o por los soviéticos. El plan de los hermanos, de una ingenuidad abrumadora, como pronto se darían cuenta, era llegar hasta Viena, donde planeaban inscribirse en la universidad. Logran recorrer aún con libertad parte de la Alemania ya destruida por los bombardeos aliados, en 1944, pero pronto son capturados por los nazis y esclavizados, primero en una fábrica, y luego, en mucho mejores condiciones, en una granja. Parte del mejoramiento de sus condiciones de vida se debió al hecho de que la destrucción a gran escala, en la Alemania nazi, fue un fenómeno estrictamente urbano: mientras las ciudades eran masivamente bombardeadas por la aviación aliada, el campo constituía un lugar de refugio relativamente seguro.

Con la rendición, los Mekas se convierten en refugiados, y vagabundean por Alemania buscando, antes que nada, sustento, y casi con la misma necesidad, libros ${ }^{11}$, estudios y el permiso de partir como emigrantes a cualquier destino. El regreso a Lituania es imposible puesto que el país ha sido ocupado por los soviéticos. Así, en el transcurso de unos cuantos meses, Mekas conoció la condición de viajero, esclavo, refugiado, estudiante y emigrante, y anotó un diario en el que se consignan estas transformaciones casi de paso: la verdadera metamorfosis de Mekas tiene lugar durante su huida de Alemania y Europa, a la par que recobra su identidad y las ruinas de las ciudades empiezan a desaparecer.

A pesar de las experiencias traumáticas que narra y del territorio de desolación que se recorre, el diario está escrito con sobriedad, con laconismo, muchas veces como una simple consignación de los hechos. Rara vez se leen reproches o quejas proferidas contra los nazis, los soviéticos o los aliados, que parecen limi-

\footnotetext{
Llama la atención que en las ciudades alemanas, incluso ya en el periodo de los bombardeos, sobrevivía la vida cultural. Y aún más llamativo es el hecho de que en los campos de refugiados hubiera comercio de libros, y que en las ciudades de posguerra, a pesar de la enorme escasez de productos básicos, hubiera librerías y bibliotecas en funcionamiento.
} 
tarse a cumplir con su papel: esclavizar, invadir y bombardear, respectivamente. A veces, es perceptible un tono ligeramente lírico, del que el autor es consciente, y que justifica con el recordatorio constante de que quien escribe es un poeta. En otros momentos, se puede percibir cierto desdoblamiento, recurso sin el cual, quizá, la escritura no hubiera sido posible debido al profundo dramatismo de las escenas que se narran; el propio Mekas invita a leer su diario de esta forma:

Invito a leer todo esto como un fragmento de la vida de alguien. $\mathrm{O}$ como una carta de un extranjero que siente nostalgia. $\mathrm{O}$ como una novela, ficción pura. Sí, invito a leer esto como una ficción. El tema, la trama que anuda estas piezas, es mi vida, mi desarrollo. ¿El villano? El villano es el siglo XX. (Mekas 2017: 160-161)

Mekas, por su condición múltiple, es ya un testigo privilegiado; pero lo es aún más por haber presenciado el final de la guerra en la Alemania nazi, por haber padecido los bombardeos aliados, por haber presenciado la llegada de los soldados británicos, por haber contemplado el paisaje de desolación, por haber formado parte del inicio de la reconstrucción y, finalmente, por haber abandonado una Europa que lo había destruido con la misma saña con que se había destruido a sí misma.

Al cruzar la frontera e internarse en Alemania, ya son perceptibles los efectos apocalípticos de los bombardeos aéreos. En un primer momento, como es de esperarse, la magnitud del desastre capta la atención del recién llegado, quien aprende a leer los signos que burocratizan y hasta cierto punto normalizan el derrumbamiento: "Visita a Hamburgo. Sólo una pila de escombros. [...] Hay cruces negras pintadas sobre muchas de las pilas de ladrillos. Eso significa que los ocupantes de esos edificios aún están enterrados bajo los escombros" (Mekas 2017: 54). La preocupación del gobierno nazi, ya casi derrotado pero aún en funciones, no era la población civil, sino el resguardo de la infraestructura que hiciera posible la continuidad de la guerra. Mekas advierte como un mal augurio la reconstrucción de las fábricas, y pronto terminaría esclavizado dentro de una de ellas: "Un suburbio bombardeado de Hamburgo. Alguna vez fue una bella ciudad. Aún ahora es sorprendente cuántas fábricas hay en funcionamiento. Las casas están destrozadas, pero no dejan de reconstruir las malditas fábricas" (Mekas 2017: 51).

Las descripciones de las ciudades destruidas van desapareciendo del diario, por haberse convertido en un paisaje cotidiano y natural, del que ya no se puede decir nada nuevo. Solo cuando hay un detalle distinto y llamativo, la destrucción regresa al diario. En general, estos detalles tienen un carácter metafórico, relacionado con la analogía ciudad-sociedad propuesta por Enzensberger:

En Kassel nos quedamos sin comida y sin agua. Caminamos kilómetros a través de las ruinas en busca de la Ernehrungstamt (Oficina de Permisos de Comida). Nadie a la vista. Solo ocasionalmente encontramos a alguna persona por el camino de arcilla y concreto cavado en montañas de devastación. A veces sobre las pilas de escombros vemos hombres y mujeres limpiando, juntando ladrillos, poniéndolos en pilas ordenadas. Desde otra montaña de desechos se podía ver humo: alguien debe estar viviendo muy en lo profundo, bajo los ladrillos. Y aquí parecería que hubo una iglesia. Con los brazos señalando el cielo, sin las cabezas, yacen dispersos los santos. (Mekas 2017: 105)

En la entrada anterior, correspondiente a julio de 1945, ya con la rendición consumada, Mekas adivina las ruinas de una iglesia por los indicios de los santos desperdigados, rotos. Esta reconstrucción mental de lo que había antes, de lo que habían formado los escombros, es un proceso continuo en el que también se lee la descripción de una sociedad rota, de la que no resulta sencillo identificar dónde se asientan, o dónde se asentaron, sus pilares fundamentales:

Caminamos por Würzburg. Miramos a la izquierda, miramos a la derecha: es un desierto, no hay nada a la vista. Ni siquiera un fantasma. Nada se mueve. Nadie camina por estas calles ahora, no tienen motivos. No hay ni un edificio entero a la vista. El aire huele a humo y a cuerpos descompuestos, hundidos bajo los ladrillos y el concreto. Aquí están las ruinas de un teatro, y aquí están los restos de una iglesia. Aquí, parece, había una universidad. (Mekas 2017: 109) 
No podrían resultar más elocuentes las ruinas que intuye Mekas: un teatro, una iglesia y una universidad. Dicho en otras palabras, el arte, la fe y la cultura, centros simbólicos en torno de los cuales se erigen las urbes y la sociedad, habían dejado de existir: ya eran solo piedra y polvo. Y si el simbolismo de esos escombros puede trasladarse de la ciudad a la sociedad alemana, también pueden trasladarse al mismo Mekas, quien, esclavizado, había abandonado la escritura poética, la esperanza y el conocimiento.

Con la rendición de la Alemania nazi, el contenido del diario empieza a cambiar: ya no solo se consignan hechos, sino que las entradas se vuelven un poco más introspectivas. Mekas recobra su identidad conforme intenta huir de las ruinas, por imposible que parezca: "Todos nos aconsejan permanecer en Würzburg. No queremos; es muy deprimente contemplar las ruinas a cada momento" (Mekas 2017: 111). Lo experimentado por el poeta lituano puede extrapolarse también a lo que había sobrevivido de la sociedad alemana. Ahora bien, solo había dos alternativas para dejar las ruinas atrás: huir o reconstruirlas. La elección no es lo que importa, lo prioritario es dejar la guerra, y su herencia más concreta y visible, las ruinas, en el pasado:

Hasta este momento mi vida parece haberse deslizado por el mundo real sin participar, como ajena, desconectada. Incluso cuando me encontraba en el centro mismo de los acontecimientos, en realidad no estaba allí [...].

No quiero conexión con este mundo.

Busco otro mundo en el que valga la pena conectarse. (Mekas 2017: 149)

Con la introspección, también surgen fragmentos de escritura que reflexionan sobre ella misma; Mekas se cuestiona si, ocupado en sobrevivir, no gasta mucho espacio contando cómo consigue alimentos. Esta inquietud recuerda el argumento de Enzensberger, según el cual la desesperación de los alemanes por satisfacer sus necesidades básicas volvió imposible una mirada sobre las circunstancias:

Estoy avergonzado de la cantidad de espacio que le dedico en mi diario a lo que comemos. Sé que muchos lectores me abandonarán por esto. Pero es la realidad de nuestra vida cotidiana en estos días. Uno trata de aferrarse al espíritu pero gana el estómago. La irregularidad y la miseria de la comida que obtenemos nos mantiene conscientes todo el tiempo de nuestros estómagos. (Mekas 2017: 190)

La errancia por la Alemania derrotada continúa, de campo de refugiados tras campo de refugiados, en búsqueda de alimento y, también, de un permiso para emigrar a donde sea: Israel, Egipto, Estados Unidos. Conforme la posibilidad de emigrar parece más cercana, Mekas se sigue desprendiendo de las ruinas y del letargo en el que lo había sumido la guerra, en un proceso voluntario y consciente: "Es tan poco lo que queda después de esta guerra que no esté cubierto de basura, de vergüenza y traición. Así que uno quita el polvo y los ladrillos y lee" (Mekas 2017: 198).

Estar preparando su partida no le impide a Mekas asistir a la universidad a tomar clases de literatura y filosofía. Si bien el lituano no levanta edificios, sí participa en la reconstrucción civil del tejido cultural alemán; asiste a conciertos en los que por primera vez en una década se tocan composiciones de Mendelssohn, Mahler y otros músicos judíos, hasta entonces prohibidas por considerárseles música judía; funda y dirige una revista literaria en lituano; publica un libro de poemas del que se venden cuatro ejemplares, lo que lo llena de alegría, y toma fotografías con una cámara recién adquirida, con lo que sienta las bases de su futura carrera de cineasta, que tendría que esperar dos décadas para concretarse. Su actividad artística y cultural renace, sin duda, $\mathrm{y}$, simultánea y significativamente, las ruinas desaparecen:

Dejo el aula y camino por las inmediaciones de la universidad. La cabeza me da vueltas. Voy hasta el Rin. Me quedo parado largo rato, quizás una hora, sobre el puente, inclinado sobre la baranda contemplando el río. Pequeños barcos y gaviotas. Puedo oír el ruido de los camiones sobre la orilla del norte, limpiando los escombros de la guerra. (Mekas 2017: 148)

Sebald parece tener razón, y el proceso de reconstrucción no permite reflexionar sobre lo caído. Mekas quiere dejar todo atrás y partir hacia Estados Unidos, donde imagina, con ra- 
zón, que encontrará una vida nueva, en la que podrá realizarse como artista, y un país entero para habitar. Será para siempre un refugiado y nunca pertenecerá realmente a ninguna parte, pero al menos, en consonancia con la sociedad alemana, que no tuvo tiempo, ánimo ni ganas de detenerse en lo caído para contemplarlo, dejará la guerra atrás: "Lenta, lentamente, el sufrimiento de la guerra abandona el cuerpo y el alma, muy lentamente" (Mekas 2017: 120). Para que este abandono fuera definitivo, había que refundar, olvidar y callar: los cimientos y las estructuras de las nuevas ciudades alemanas fueron construidos con silencio.

\section{La nada como espectáculo}

El perfil del irlandés James Stern ${ }^{12}$ se apega más a la clase de testigo privilegiado por Enzensberger. De hecho, Stern es un testigo profesional por partida doble: a su labor como informante del Ejército de Estados Unidos, habría que añadir su condición de escritor.

Stern fue contratado por el Ejército estadounidense, junto con otros cuantos civiles que hablaban alemán, entre los que se encontraba el poeta W. H. Auden, para realizar una serie de entrevistas a civiles alemanes con el fin evaluar las consecuencias psicológicas y materiales de los bombardeos aliados. Dicho en otras palabras, la labor profesional de Stern consistía en escuchar y en interpretar la posguerra, en asentar en un informe la situación alrededor de la cual se estaba construyendo un pacto de silencio. Además de ese informe, de autoría colectiva y de acceso reservado, el viaje de Stern dio por resultado El daño oculto, relato de viaje que se publicó en Estados Unidos en una fecha tan temprana como 1947.

Contra lo que afirma Enzensberger, la mirada del extranjero también desborda ideología, y El daño oculto dista mucho de ser objetivo, lo que, para ser justos, en ningún momento pretende Stern. Él es consciente de todos los privilegios con los que cuenta y de la incomodidad de su posición: recibir un salario generoso por asentar en un papel la desgracia

\footnotetext{
Políglota, trotamundos y hombre de mundo, James Stern (1904-1993) fue un escritor reconocido en su tiempo. Fue testigo de algunos de los acontecimientos más importantes del siglo XX, y formó parte, a lo largo de su vida, de distintos grupos de artistas, lo que le permitió entablar una amistad cercana con figuras como Christopher Isherwood, James Joyce, Samuel Beckett y W. H. Auden.
}

de los demás. Su uniforme le confiere poder y sus impresiones se producen desde el bando vencedor. Stern era un hombre sumamente culto; además de dominar el alemán, había vivido varios años en ese país, lo que le permitió hacer una comparación de las circunstancias alemanas de antes de la Guerra y de después. Para Stern, en cierta medida, el nazismo fue un paréntesis, crucial pero paréntesis al fin y al cabo, pues abandonó Alemania justo antes de que Hitler tomara el poder, y regresó a lo que quedaba del país un par de meses después de que lo perdiera. Con estos antecedentes, era de esperar una actitud de empatía, que está presente sobre todo cuando el informante se encuentra con viejos conocidos, algunos de ellos auténticas víctimas y opositores al nazismo, y cuando recorre los lugares en los que fue feliz de joven, y que ahora resultan irreconocibles.

No obstante, la empatía e incluso la compasión por el pueblo alemán, que experimenta por momentos, por más que nunca dude de que esa destrucción es merecida, se ve opacada por cierta frivolidad de viajero de alto status que se regodea en la miseria de los nativos. Stern tiene claro que, por más que sufran, los alemanes lucen más sanos y menos flacos que los habitantes de las naciones a las que invadieron, como Francia o Bélgica, y no se diga Rusia o Polonia. Además, de manera frecuente hace hincapié en el comportamiento civilizado del ejército estadounidense de ocupación, en contraste con el salvajismo de la Gestapo. Y, por si fuera poco, Stern se muestra convencido de que los bombardeos aéreos "totales", sin fines militares concretos, sino como mera represalia contra el pueblo alemán, eran un acto de elemental justicia. Estas justificaciones morales le permiten admirar la destrucción sin conmoverse, e incluso cayendo en el morbo. Para Stern, la devastación alemana es, ante todo, un espectáculo no tan distinto del que se podía gozar en un teatro, como deja claro en una escena de Núremberg, ciudad a la que desprecia especialmente por ser la "capital" del antisemitismo alemán:

Al mirar hacia arriba, veías un decorado traído directamente del teatro isabelino: hombres y mujeres sentados en sillas en una habitación del tercer piso de una vieja casa que había perdido su fachada. El rostro de la casa -su pared frontal, sus ventanas y todose había derrumbado; y aun así, mientras siguiera el tiempo agradable, los muchos 
ocupantes de la casa se sentaban cómodamente en su sala de estar, chismorreando en sus sillas, rodeados de todos sus objetos familiares, y pretendían no saber que si daban tres pasos hacia delante caerían al caos. [...] Llegó a fascinarme tanto la vida privada pública de esta familia que solía detenerme, escondido entre las ruinas, y mirarlos vivir. (Stern 2010: 361)

Con todo y las enormes diferencias de su condición, las etapas que experimenta Stern frente al arrasamiento de las ciudades alemanas son similares a las de Mekas. En primer término, por supuesto, hay una reacción de pasmo e incredulidad ante las dimensiones de la nada:

A la mente le lleva un largo tiempo asimilar la destrucción a semejante escala. Tienes que vivir en ella para creerla. Al principio piensas en ella no como la destrucción, como algo hecho deliberadamente al hombre por el hombre, sino como un terremoto -el Terremoto, el fenómeno de nuestra era-. Nada de lo que vi en Frankfurt perduraba tan intacto como para convencerme de que alguna vez había estado realmente yo allí en el pasado. (Stern 2010: 111)

Pero más rápidamente de lo que podría pensarse, el testigo se acostumbra a la devastación. Esta no cambia, y su permanencia provoca que Stern la naturalice. De hecho, a la rutina de su trabajo (realizar cada día varias entrevistas, siempre con las mismas preguntas, elaboradas por los servicios de inteligencia, algunas de ellas absurdas), hay que sumar la monotonía de las ciudades, todas similares, unas a otras, y quizás más desesperadamente, siempre a sí mismas, en su aniquilación:

No miré atrás, seguí mi camino, probablemente a mucha velocidad. No me acuerdo. Solo recuerdo que volví a ver -al pasar bajo los arcos para entrar y salir de Memmingen- lo que había visto un mes antes: los restos destrozados de las pocas casas que habían quedado en pie en la Ciudad Vieja de Frankfurt. (Stern 2010: 254)

Al igual que al viajero la devastación deja de sorprenderle, una buena parte de la sociedad alemana hizo lo mismo con los bombardeos y sus secuelas. Estos llegaron a formar parte de la cotidianidad, a tal grado que se convirtieron, literalmente, en juego de niños, como consigna Stern, esta vez sí sorprendido:

En la acera junto a la verja de nuestra casa provisional, había dos niños jugando sobre un montón de arena. Uno de ellos sostenía en la mano un viejo recipiente de lata, mientras el otro construía una especie de castillo de arena. De repente, el niño del tarro emitió un sonido ululante, como el de una sirena. El otro niño saltó hacia atrás, tomó un segundo tarro, lo llenó de arena, y juntos, con los tarros encima de sus cabezas, los dos comenzaron a hacer ruidos como de aviones en vuelo. "¡Soy un amerikaner!”, gritaba uno. "¡Yo soy un engländer!”, proclamaba el otro. Y juntos, con un amplio agitar de brazos y un atronador " $;$ boom!, ¡boom!, ¡boom!”, dejaron caer sus tarros llenos de arena sobre el castillo, rodaron ellos mismos sobre sus ruinas, y estallaron en carcajadas. (Stern 2010: 330)

Gradualmente, las descripciones de las ruinas van desapareciendo de las páginas del relato. Llega un punto, incluso, en que ya ni se las nota; su presencia es tan evidente que no hace falta remarcarla. Este proceso es hasta cierto punto consciente, pues el mismo Stern afirma que, cuando podía, huía al campo para descansar de la destrucción, y no le resultaba fácil regresar a las ruinas, monótonas e inmutables:

A mediodía no regresábamos a Núremberg, sino que comíamos emparedados preparados por Hans y frau Miedel en las afueras de la ciudad, en el bosque de pinos, y nos echábamos allí, en silencio, debajo de los árboles, y conversábamos o dormitábamos hasta que se hacía la hora de regresar a la entrevista de la tarde. Cuando esta se terminaba, solíamos regresar paseando, despacio y con reticencia, hasta las ruinas. (Stern 2010: 393)

Gracias a su conocimiento del pueblo y de las lenguas del nazismo y a haber sido testigo de la ascensión del nazismo, recursos con los que no contaban muchos de los testigos leídos por Enzensberger, a los que hay que sumar 
las docenas de entrevistas realizadas por él y por sus compañeros, Stern tiene una opinión autorizada a la hora de caracterizar el estado del espíritu alemán, si tal empresa podía llevarse a cabo. Stern expresamente se cuida de formular generalizaciones, pero algunas veces, por fortuna, cae en la tentación y lo hace, por ejemplo, cuando se pregunta si los alemanes experimentan un sentimiento de culpa tanto por las atrocidades cometidas como por la situación de deriva en la que se encontraban. La respuesta es tajante:

¿Expresaban los alemanes algún sentimiento de culpa? Con la excepción de ejemplos como los que se citan a partir de las entrevistas, la respuesta es definitivamente no. Nuestra explicación a este fenómeno es simple: que el sentimiento de culpa entre los alemanes es tan colosal que simplemente no pueden afrontarlo, mucho menos expresarlo. (Stern 2010: 166)

Stern a veces se desespera con el provincianismo y la ignorancia alemanes, cuando, por ejemplo, los entrevistados no parecen nunca haber pensado en el sufrimiento que otros pueblos experimentaron durante la Guerra. Sin embargo, lo que prevalece es una actitud esquiva y reticente a hablar, algunas veces motivada por la desconfianza (el entrevistador no dejaba de ser un miembro del ejército de ocupación), y otras, la mayoría, por una incapacidad de afrontar tanto la realidad del pasado inmediato como del presente ${ }^{13}$.

Los entrevistados rara vez manifiestan preocupaciones políticas u opiniones definitivas sobre la Guerra. Las veces que adquieren confianza, se limitan a formular preguntas y a hacer comentarios sobre sus necesidades más inmediatas, que son básicamente tres: la muerte o la ignorancia del paradero de familiares, amigos y vecinos; cómo conseguir comida, y la precariedad de sus viviendas. En repetidas ocasiones, la única preocupación política que manifiestan es el riesgo de que los estadounidenses se retiren de Alemania y esta sea inme-

Piénsese también que el nazismo había prometido un estado utópico que no podía resultar más lejano que la realidad a la que se enfrentaban los sobrevivientes alemanes: "El comunismo y el nazismo ario se arrogaban el modelo de sociedad utópica. En el primer caso, la 'abolición de la explotación del hombre por el hombre'; en el segundo caso, el advenimiento del "superhombre"' (Vallejo-Gómez 2011: 132). diatamente ocupada por las tropas soviéticas. Más que ideológica, la motivación de esta angustia era el simple temor de las represalias rusas, tras la campaña de devastación llevada a cabo por los nazis en el Frente Este.

Finalmente, Stern concluye su viaje y su relato con la certeza de que poco pudo averiguar sobre el estado de ánimo de la población alemana, o los pensamientos que albergaba, aparte de la evidente (pre)ocupación por intentar sobrevivir. El silencio que más le llama la atención es el que rodea a los efectos devastadores de los bombardeos, y, a su pesar, acepta que "me di cuenta, como no lo había hecho hasta entonces, de que un abismo se interpone entre aquellos que han visto y aquellos que no, un abismo que la palabra hablada no puede franquear" (Stern 2017: 461).

\section{El olvido fecundo}

Para Stern, las causas del silencio alemán son la profunda vergüenza por el sufrimiento infligido a las naciones vecinas y a los judíos, y también por la derrota y su secuela de miseria y caos. Aunque nunca lo expone con tal claridad, Mekas, mediante su diario y, por tanto, mediante su vida, aventura que el olvido es el precio que hay que pagar por continuar viviendo. Y no cualquier vida, sino una en que la realización artística y el ejercicio de la libertad estén aseguradas. No deja de ser significativo que Mekas se convirtiera en un cineasta radicalmente experimental, y no en uno testimonial.

Sin citar a ninguno de los dos autores antes mencionados, Sebald parece coincidir con ambos, y es enfático al afirmar que

la muerte por el fuego en pocas horas de una ciudad entera, con sus edificios y árboles, sus habitantes, animales domésticos, utensilios y mobiliario de toda clase tuvo que producir forzosamente una sobrecarga y paralización de la capacidad de pensar y sentir de los que consiguieron salvarse. (Sebald 2003: 34)

Para volver a levantar "la ciudad entera" de la que habla Sebald, el olvido no era una alternativa, sino un requisito. A este hecho, habría que agregar una realidad muy incómoda en la actualidad, cuando la memoria histórica, tras 
el catálogo de horrores del siglo XX, se considera un imperativo moral: la sociedad alemana mostró una memoria pertinaz tras la Primera Guerra Mundial, a diferencia de la Segunda, en la cual prevaleció el olvido. En lo que respecta al caso alemán en exclusiva, resulta evidente qué reacción terminó siendo preferible ${ }^{14}$.

Esta reivindicación del olvido es un tema de actualidad, a pesar del rechazo inicial que provoca y de la profunda incorrección política, e incluso moral, en la que se basa. Al respecto, el periodista y analista David Rieff, significativamente fundador del proyecto "Crímenes de guerra" y autor de Elogio del olvido, escribe:

Dadas las tendencias agresivas de la humanidad, es posible como mínimo que el olvido, a pesar de todos los sacrificios que impone, sea la única respuesta prudente; y en ese sentido debería ofrecer cierto consuelo más que causar consternación. (Rieff 2017: 4)

Cuestionable en términos históricos y morales, el olvido al que se condenó y se sigue condenado a la inédita destrucción de las ciudades alemanas de la Segunda Guerra Mundial fue un requisito para la reconstrucción y, paradójicamente, para la paz. Los cimientos de la Europa contemporánea, como ya se mencionó, están erigidos sobre el silencio y el olvido, sobre ruinas que se quedaron sin palabra y que tampoco tienen palabra. Si hablaran, ignoramos los efectos que su voz podría tener.

\section{Bibliografía}

Bessel, Richard (2012): "Leaving Violence Behind: Thoughts on the Development of Germany after 1945”, Historia 396, núm. 2, pp. 181-195.

Enzensberger, Hans Magnus (2013): Europa en ruinas: Relatos de testigos oculares de los años 1944 a 1948. Madrid: Capitán Swing.

Lejeune, Philippe(1975): Le pacte autobiographique. París: Seuil.

Ley Brandt, Isabela (2009): "El papel de Alemania en la construcción de la memoria colectiva y de la identidad cultural europea", Revista Universitaria Europea, núm. 11, pp. 101-116.

Mekas, Jonas (2017): Ningún lugar adonde ir. Buenos Aires: Caja Negra.

Pistolato, Franceso (2016): "Alemania y la superación de traumas: Del militarismo al pacifismo", Ámbitos: revista de estudios de ciencias sociales y humanidades, núm. 36, pp. 17-28.

Rieff, David (2017): "Cumplir con el deber de olvidar", Ideas, El País, 19 de marzo de 2017, pp. 2-4.

Sebald, W. G. (2003): Sobre la historia natural de la destrucción. Barcelona: Anagrama.

Stern, James (2010): El daño oculto. Madrid: Lengua de Trapo.

Vallejo-Gómez, Nelson (2011): "Humanismo y terror", en Beatriz Nates (ed.), Memoria, espacio y sociedad. Barcelona: Anthropos, pp.117-134.

Por supuesto, el inesperado pacifismo alemán tiene muchas otras explicaciones, como la reeducación del pueblo alemán que emprendieron los aliados, así como la labor de distintos investigadores para la paz (véase, por ejemplo, Pistolato 2016). 